\title{
Proses Penyajian Kolaborasi Angklung dan Orkestra pada Aransemen Lagu Radetzky March Di SD Budi Mulia Dua Yogyakarta
}

\author{
Wahyudi \\ Program Studi Seni Musik, FSP Institut Seni Indonesia Yogyakarta, 0818468737; yudi_041@yahoo.com \\ Ayub Prestiyo \\ Program Studi Pendidikan Musik, FSP Institut Seni Indonesia Yogyakarta; \\ 0818274677biru_bening@yahoo.co.id.
}

\begin{abstract}
This researcch is focused on musical arrangement of the angklung and orchestra collaborative performcance process as a part of the Yogyakarta Second Budi Mulia Primary School extra curricular project. It is done within qualitative research frame work, and specifically approached through developmental method. That is a research process that study its subject as musical practitioners. This study concludes that the collaborative work of the angklung and orchestra would contribute to an interesting and innovative performance if it is supported by a good musical arrangement which is based on the angklung registers and the motoric skills of children.
\end{abstract}

Keywords: the angklung, orchestra, arrangement.

\begin{abstract}
Abstrak
Penelitian ini menitik beratkan pada aransemen dan proses kolaborasi penyajian angklung dan orkestra di Sekolah Dasar Budi Mulia Dua Yogyakarta. Jenis penelitian yang dilakukan menggunakan metode kualitatif dengan pendekatan developmental yaitu sebuah proses penelitian yang mempelajari subyek sebagai pelaku musik. Hasil penelitian mendapatkan bahwa penyajian angklung dan orkestra bisa menjadi pertunjukan yang menarik dan inovatif jika ditunjang dengan aransemen yang baik berdasarkan jangkauan nada-nada angklung dan kemampuan motorik anak.
\end{abstract}

Kata Kunci: angklung, orchestra, aransemen.

\section{Pendahuluan}

Sebagai sebuah hasil kreasi budaya, angklung mengalami perubahan bentuk dan fungsi sesuai perkembangan jaman. Walaupun demikian, dilihat dari bahan dasarnya, angklung terbuat dari batang bambu yang dipotong sedemikian rupa sehingga membentuk wujud angklung seperti yang dikenal pada saat ini. Teknik permainannya dilakukan dengan cara digetarkan hingga dipukul menggunakan stik khusus.
Menurut Budi,

(2015:139-140), lingkungan masyarakat Indonesia yang masih sangat kental dengan nilai-nilai kehidupan agrarisnya, sebagian besar seni pertunjukannya memiliki fungsi ritual. Berkaitan dengan hal tersebut maka keberadaan angklung dalam kehidupan masyarakat Sunda berfungsi untuk menjalankan budaya ngahuma atau berladang atau yang berhubungan dengan padi. Contoh angklung sebagai fungsi ritual terlihat pada angklung dodog lojor dalam upacara seren tahun. Angklung ini 
dimainkan sebagai salah satu media berdo'a atau syukuran atas keseimbangan alam hingga melimpahnya hasil bumi. Menurut Wiramiharja (2010:4-9) Selain berfungsi sebagai ritual tanam padi, angklung juga berfungsi sebagai pengganti genta (bel) dalam ritual keagamaan (persembahyangan).

Sumarsana (2007: xxiii) pada awalnya titi laras (tangga nada) angklung adalah laras pelog dan laras slendro. Kemudian menjelang Indonesia merdeka angklung diubah dalam tangga nada diatonik oleh Daeng Soetigna sekitar tahun 1938. Beliau adalah orang pertama yang mengadopsi ilmu musik Barat untuk mengkreasi perubahan tangga nada tersebut. Berawal dari situlah kemudian angklung bisa memainkan lagu-lagu yang bertangga nada diatonis.

Seiring perkembangan jaman, instrumen angklung sebagai warisan budaya masyarakat Sunda mampu bertahan dan tetap eksis. Budaya popular yang menggerus masyarakat Indosnesia lewat teknologi media massa, seolah tidak mampu mengkerdilkan eksistensi musik angklung. Hal ini tentunya tidak lepas dari peran pemerintah dan pelaku kesenian musik angklung. Seperti yang dilakukan oleh padepokan seni Saung Angklung Udjo: Sundanese Art \& Bambo Craft Center yang mengemas pertunjukan musik angklung sebagai komoditas wisata.

Kehadiran musik ditengah-tengah masyarakat tidak terlepas dari peranan yang cukup besar dari seorang komponis/aranjer dalam menyampaikan ekspresi melalui instrumen. Dalam proses penyampaian ide musikal seorang komponis/aranjer dapat melakukan banyak hal, selain menyusun ide tersebut ke dalam sebuah komposisi musik, dapat menuangkan idenya dalam bentuk aransemen. Menurut Randel (1986: 53) definisi kata "aransemen" dapat diartikan dengan menyadur suatu komposisi yang berlainan dari komposisi aslinya, biasanya dengan tujuan mempertahankan unsureunsur esensi musikalnya, juga dengan suatu proses adaptasi yang sedemikian rupa.

Aransemen sangat erat hubunganya dengan sebuah kreatifitas. Seorang arranger dituntut untuk dapat mengolah sebuah karya musik yang akan di aransemen, agar karya musik tersebut menjadi lebih artistik dengan nuansa dan suasana baru. Salah satu contohnya adalah dengan cara mengembangkan ide dari tema asli ataupun membuat variasi. Variasi merupakan ide tematis yang dapat dihasilkan dengan mengolah elemen musikal, yaitu melodi, ritme, harmoni, dinamika, timbre dan ekspresi. Seorang arranger biasanya mendasarkan kerjanya pada sebuah karya jadi (lagu atau pun musik yang sudah ada), sehingga tidak terikat pada apapun dalam proses kerja kreatifnya, lebih leluasa menggunakan instrumen musik, dan format sesuai keinginan dalam mengaransemen karya musik. Kaitan dalam hal ini adalah arranger mengkolaborasikan ansambel angklung dengan orkestra agar mendapat suasana yang berbeda.

\section{Pembahasan}

\section{Angklung Dan Sekolah Dasar Budi Mulia Dua Yogyakarta}

Secara historis kedudukan dan fungsi angklung mengalami perubahan atau modifikasi sebagai akibat dari persinggungan dengan seni modern, hingga bisa dinikmati sebagai tontonan dan hiburan seperti sekarang ini. Menurut Haviland 1993:246 perkembangan suatu kebudayaan sesuai dengan tuntutan zaman merupakan produksi perubahan dari waktu ke waktu yang dapat disebabkan dari berbagai hal. Salah satu sebabnya adalah perubahan lingkungan yang dapat menuntut 
perubahan kebudayaan yang bersifat adaptif. Pada awalnya instrumen angklung menggunakan tangga nada pentatonis namun perkembangan yang terjadi selanjutnnya adalah pada tahun 1938 Daeng Soetigna berhasil merubah angklung pentatonis menjadi diatonis (do-re-mi-fasol-la-si-do).

Sekolah Dasar Budi Mulia Dua Yogyakarta Sekolah ini beralamat di Jalan Seturan No. 15 Depok Sleman. Aini (2013:3841) mengatakan bahwa Budi Mulia Dua Yogyakarta sebagai institusi pendidikan juga menetapkan misi untuk membantu anak agar tumbuh dan berkembang sesuai potensi yang dimiliki, memberi pendidikan dasar dengan kurikulum yang tidak membebani siswa-siswi serta menyediakan sarana dan prasarana yang membuat siswa menyukai sekolah. Misi tersebut dijabarkan dalam delapan basis pembelajaran, yaitu 1) pengakuan bahwa setiap individu adalah unik; 2) penghargaan pada prestasi; 3) pendidikan berbasis living values; 4) orientasi kelugasan berpikir dan bertindak; 5) pembelajaran sebagai proses terbuka partisipatoris; 6) penghargaan dan toleransi pada perbedaan;7) agama,seni, dan olah raga sebagai praktik; dan 8) disiplin positif. Basis tersebut menjadi pilar penyangga layanan sekolah dalam menghargai potensi indvidu anak. Tujuan yang hendak dicapai agar sekolah dapat mendampingi siswasiswi dalam belajar dan mengembangkan potensi sehingga menjadi manusia yang berakhlak mulia, cerdas dan terampil.

Secara networking, menurut Arfani 2013:77-79 Budi Mulia Dua Yogyakarta banyak menjalin kerjasama dengan institusi sejenis baik nasional maupun internasional, antara lain Vladislava Vancury di Rebuplik Cheko, frutigen Oberstufenschule dan Music School 1,2,3 Sion Swiss, Sekolah no. 39 di Beijing, The Piedmont Children Choirs Sanfransisco di USA, Ritsumaikan High school
Kyoto di Jepang dan Camborne Science High School di UK. Hubungan tersebut dilakukan dengan saling mengunjungi guna memperoleh gambaran yang komprehensif mengenai latar belakang kultural, musik, humanistic dan science.

\section{Orkestra Budi Mulia Dua}

Menurut Taylor (2004:231-233) Orkestra adalah penggabungan kelompok instrument string, tiup kayu, tiup logam dan perkusi yang dipimpin oleh seorang kondakter. Saat ini orkestra diartikan sekelompok instrument yang mencakup string, tiup kayu, tiup logam dan perkusi dan jumlah yang dibutuhkan hampir tidak pernah ditentukan oleh komposer. Terbentuknya orkestra Budi Mulia Dua berawal dari pelajaran musik yang wajib ditempuh dalam dua jam setiap minggu. Selain dari pelajaran musik juga ektrakurikuler yang meliputi, paduan suara, ansambel biola, ansambel gitar, band dan angklung. Sebelum masuk ekstrakurikuler khusus untuk biola, gitar, piano, drum harus mengikuti kelas privat dalam satu tahun karena ekstrakurikuler bersifat ansambel yang sudah harus bisa membaca not musik untuk bermain bersama. Kemudian bagi siswa sudah mampu membaca not musik dimasukkan dalam ekstrkurikuler. Dalam proses pembelajaran musik di Budi Dulia Dua mengalami peningkatan yang signifikan baik secara kualitas maupun kuantitas. Artinya adalah secara kualitas pendidikan dibidang musik terutama vokal dan instrument biola mengalami peningkatan kemajuan dan secara kuantitas minat siswa untuk belajar musik setiap tahunnya mengalami peningkatan jumlah.

Pada acara tertentu ansambelansambel tersebut selalu tampil. Dalam sebuah acara di sekolah Budi Mulia Dua mendapat kunjungan B.J Habibie mantan Presiden RI dan menyaksikan ansambel 
biola. Selain menyaksikan pertunjukan siswa-siswi, mantan presiden juga sangat mendukung keberadaan ansambel tersebut dan berharap agar dikembangkan menjadi orkestra. Respon baik dari pihak yayasan Perguruan Budi mulia Dua maupun mantan presiden tersebut maka diwujudkan dengan mendirikan orkestra yang merupakan pengembangan dari ansambel-ansambel tersebut.

Melihat dari perkembangan ansambel yang semakin menunjukkan peningkatan yang signifikan, kemudian guru dan pengurus Budi mulia Dua timbul gagasan untuk menggabungkan ansambelansambel yang sudah ada untuk dibentuk menjadi orkestra. Menurut Dewanta konser perdana yang dilaksanakan (2013:3-4) tepatnya 1 Juni 2011 dalam acara wisuda dan dilanjutkan konser bertema Malam Inagurasi Siswa pergelaran Grand Orkestra dan paduan suara. Lebih dari seratus siswa menunjukkan ketrampilan dalam memainkan alat-alat musik orkestra dan seratus anak dalam tim paduan suara melantunkan berbagai lagu.

Jumlah pemain orkestra Budi Mulia Dua mengalami jumlah yang tidak pasti dan mengalami perubahan, namun sebagai gambaran di konser tahun Juni 2015 yang bertema Story of Journey, terdiri dari kelompok string Biola 1 ada 14 pemain, Biola 2 ada 14 pemain, biola alto ada 4 pemain, Cello:4, Kontrabas:1. Kelompok tiup kayu terdiri dari Flute 2, Oboe 1, Klarinet 2, Fagot 1. Kelompok tiup logam Horn 2, Trumpet 2, dan Trombone 2. Kelompok perkusi, Timpani, Grandcassa, Snardrum. Dilihat dari jumlah tersebut diatas maka bisa dikatakan sebagai orkestra.

Disisi lain, minat siswa terhadap musik mengalami peningkatan di setiap tahunnya. Maka pada tahun 2007 Sekolah Budi Mulia Dua membuat suatu wadah untuk menampung bakat dan minat siswa khususnya musik. Wadah tersebut adalah manajemen musik yang didanai oleh yayasan Budi mulia Dua untuk mengelola yang berkaitan dalam bidang musik. Manajemen musik berfungsi mengelola baik pemasukan maupun pengeluaran pendanaan, membuat jadwal latihan, menyediakan guru dan pengadakan materi ajar serta mengelola siswa yang sesuai minat dan bakatnya. Selain itu, mencari eventevent diberbagai acara baik didalam maupun diluar sekolah juga termasuk promosi.

Konser musik yang dilakukan orkestra Budi Mulia Dua Yogyakarta antara lain, 1) tahun 2012 paduan suara melawat ke Amerka Serikat dalam acara Festival Golden Gate; 2) Tanggal 23 Agustus 2013 konser dalam rangka Ulang Tahun Partai Amanat Nasional yang ke 15 di Concert Hall Convention Center, Jakarta; 3) tahun 2015 Collaboration Concert Angklung and Choir Budi Mulia Dua International With KippenbergGipnasium, Bremen Jerman.

\section{Problematika Dan Proses Pelatihan Ansambel Angklung}

Angklung diadakan atas usulan guru musik untuk mengembangkan musik tradisi selain instrumen musik orkestra yang sudah berjalan. Ansambel angklung pada awalnya dibentuk setelah Budi Mulia Dua Yogyakarta melakukan pembelian angklung tahun 2009 di Saung Angklung udjo. Kemudian seiring berjalanya waktu angklung masuk dalam kurikulum yang diajarkan mulai dari kelas 1 sampai kelas 6 .

Pelajaran awal yang diberikan untuk umum dan kelas satu ada beberapa, antara adalah pengenalan instrumen, cara membunyikan angklung dengan benar, posisi badan yang sesuai. Pengenalan instrumen meliputi angklung terbuat dari bambu yang dipotong dan panjang pendek dan diikat dengan rotan. Kemudian memproduksi 
suara dengan cara digetarkan tangan kanan dibawah dan memegang tangkai diatas. Posisi badan berdiri tegak menghadap kedepan, lagu yang diberikan pun masih sangat sederhana dan diulang-ulang. Selain itu masing- masing harus tahu nada angklung yang dipegang. Kemudian untuk materi kelas satu dalam memainkan lagu diiringi dengan piano atau keybord.

Kelas tiga tingkatan pengenalan angklung sudah lebih dalam misalnya lagunya sudah agak panjang seperti lagu wajib nasional dan memegang angklung masih satu dan diiringi dengan piano. Pada kelas empat sudah mulai memainkan dengan akor dan akor tersebut masih I, IV dan V. Pada kelas ini masing-masing siswa sudah diberikan memegang angklung lebih dari satu agar suara yang dihasilkan lebih keras. Kelas lima tingkatan memainkan angklung berbeda dengan sebelumnya yaitu memegang angklung yang ada ditiang gantungan dan tentunya sudah bervariasi ada yang memainkan melodi serta harmoni.

Pada tingkat permainan lagu dikelas enam ketrampilam yang diberikan sudah banyak variasi dan kreatifitas. Selain ada yang memainkan melodi dan harmoni juga bas berjalan melalui arumba. Arumba adalah keluarga angklung yang cara memproduksi suaranya dengan di pukul seperti gambang dalam gamelan. Bas berjalan mengikuti kemampuan musikal siswa dan diberikan keleluasaan sampai maksimal. Materi lagu pun bervariasi baik style pop, dangdut, jazz, rock. Selain itu angklung digabung dengan kelompok band dengan membagi angklung sebagai melodi dan band sebagai pengiring.

Materi pembelajaran dikelas merupakan syarat utama sebelum siswa masuk ansambel angklung dalam orkestra. Biasanya peminat angklung adalah siswa paduan suara karena peserta paduan suara tidak bermain instrumen yang lain seperti biola, piano, dan gitar. Pemilihan pemain angkung dilakukan ketika akan digabung dengan orkestra karena problematika didalamnya akan akan semakin komplek.

Salah satu repertoar yang mengkolaborasikan angklung dan orkestra adalah Radetzky March. Repertoar ini mengunakan tangga nada $G$ sesuai dengan yang tertulis dalam partitur. Notasi yang digunakan adalah notasi balok. Karena notasi tersebut memudahkan siswa dalam memahami lagu secara keseluruhan dan memudahkan apabila lagu mengalami modulasi. Jika siswa kurang mampu memahami not balok pembacaan notasi dilakukan dengan notasi angka. Namun, hal tersebut jarang dilakukan karena siswa yang terlibat dalam ansambel angklung telah melalui seleksi yang biasanya paham dalam membaca notasi balok.

Cara mengajarkan lagu di mulai dari pengenalan frase per frase, kemudian digabung menjadi kalimat musik. Hal ini dilakukan berulangkali agar kalimat musik tersebut dapat dimainkan tanpa membaca notasi. Kemudian cara menyeimbangkan angklung adalah dengan cara setiap siswa memainkan lebih dari dua angklung untuk mendapatkan suara yang lebih tebal. Proses latihan angklung hingga tahap pementasan memakan waktu kurang lebih tiga bulan. Ini disebabkan untuk menyelesaikan permasalahan seperti pemahaman lagu yang akan dimainkan, kendala angklung yang tidak bisa dibawa pulang sehingga tidak ada proses latihan individu, kaitan melodi yang dimainkan secara kelompok yang membutuhkan kedisiplinan dan ketepatan waktu dalam kedatangan. Berbeda dengan instrumen orkestra yang membutuhkan latihan individu untuk menambah skil untuk menguasai karya atau tehnik.

Untuk mengkolaborasikan antara ansambel angklung dan orkestra dibutuhkan latihan seksional. Artinya ansambel angklung 
latihan sendiri dan orkestra juga latihan sendiri. Setelah latihan masing-masing seksi bisa berjalan lancar kemudian dilakukan latihan gabungan. Di sini peranan kondakter sangat dibutuhkan untuk mengatur penyajian agar ke dua seksi bisa seimbang, hingga memberi interpretasi dari sisi artistik dan estetika yang tinggi sehingga menjadi pertunjukkan yang berkualitas. Penyajian lagu Radetzky March karya Johann strauss Op. 228 dikonserkan dalam rangka Ulang Tahun Partai Amanat Nasional yang ke 15 pada tanggal 23 Agustus 2013 di Concert Hall Convention Center Jakarta.

\section{Aransemen Lagu Radetzky March}

Budi Mulia Dua Yogyakarta dalam mengemas disetiap pertunjukan baik dalam ansambel maupun orkestra selalu menjalin kerja dari berbagai pihak. Kerja sama tersebut terutama dalam hal musik, adalah mengaransemen lagu agar menjadi lebih menarik. Pertunjukkan musik menjadi lebih baik karena didukung dan dibantu ahli-ahli dibidangnya. Aransemen lagu dikerjakan oleh, guru-guru musik; 1) Yuono Arifin adalah yang menciptakan Mars Budi Mulia Dua Yogyakarta; 2) Singgih Sanjaya adalah praktisi dan akademisi yang sudah terbiasa mengaransemen diberbagai orkestra di Indonesia; dan 3) Joko Suprayitno ialah praktisi dan akademisi yang biasa mengaransemen di Twilite Orkestra, Orkes Simponi Jakarta, Nusantara Simponi Orkestra dan lain-lain.

Pemilihan lagu lagu Radetzky March karya Johann Strauss Op. 228 tersebut, hal yang menarik ketika angklung digabung dengan orkestra, yaitu 1) orkestra yang pada umumnya biasa dikenal adalah musik klasik milik Eropa; 2) angklung milik Indonesia tidak hanya sekedar menarik tetapi menjadi tambahan pengetahuan bagi orang umum menambah ketrampilan baik dari pemain dan guru; 3) harmoni musik tradisi timur dan barat bila digabung menjadi sangat menarik.

Komposisi asli Radeztky March karya Johann Strauss op. 228 memiliki irama Polka dalam sukat 4/4 dengan tempo cepat lebhaft (march). Karya ini dibagi dalam satu gerakan (movement) dan ditengahnya terjadi modulasi. Lagu Radetzky March karya Johann Strauss Op. 228 aslinya dimainkan dalam D Mayor kemudian mengalami modulasi ke A Mayor. Namun dalam aransemen ini tangga nadanya adalah $G$ Mayor kemudian pindah tangga nada (modulasi) ke D Mayor pada bagian trio dengan pertimbangan masalah jangkauan wilayah nada dalam angklung. Kemudian pertimbangan lain, kesulitan dalam memainkan banyak alterasi (kruis/mol), kesulitan dalam memainkan ritme dalam tempo cepat, kesulitan penyambungan antara nada yang berbeda (legatto), kesulitan menghasilkan nada pendek (Staccato) dan tidak stabil dalam memegang kendali tempo. Maka berdasarkan pertimbangan tersebut lagu yang aslinya dalam D mayor diganti di G Mayor.

Pada umumnya lagu-lagu yang disajikan dalam konser di Budi Mulia Dua Yogyakarta membawakan lagu-lagu populer baik lagu dari Indonesia maupun dari luar. Namun khusus lagu Radetzky March karya Johan Straus diaransemen dalam orkestra oleh peneliti. Peneliti merancang penggabungan alat musik tradisi dengan instrumen orkestra agar mendapat warna suara yang berbeda.

Melodi dalam lagu Radetzky March karya Johann strauss adalah tergolong dalam musik yang ringan. Hal ini dapat dilihat dari melodi yang terkesan jarak nada yang berdekatan dan mudah dicerna. Harmoni merupakan ilmu musik yang memadukan nada dalam kelompok vertikal atau rangkaian nada. Nada-nada tersebut terdiri atas dua atau lebih yang merupakan 
kelompok trisuara atau akor. Aaron Copland 1957:47 menegaskan bahwa "By comparison with rhythm and melody, harmony is the most sophisticated of the three musical element". Harmoni dalam lagu Radetzky March karya Johann strauss mengambil unsur-unsur nada yang ada ditangga nada $G$ dan tangga nada D. Tone color atau timbre (warna suara) adalah merupakan warna suara atau nada yang terdapat dalam pertunjukan. Adapun warna suara sumber bunyinya bisa melalui alat musik yang dimainkan atau melalui suara manusia (vocal).

\section{Penutup}

Sebagai kesimpulan ialah aransemen kolaborasi antara ensambel angklung dan orkestra akan memberikan kontribusi terhadap pertunjukan musim yang menarik dan inovatif jika didukung oleh aransemen yang baik yang didasarkan atas jangkauan oktaf nada-nada pada instrumen angklung dan ketrampilan motorik anak-anak.

\section{Referensi}

Adler, Samuel. 2002. The Study of Orchestration, New York: W.W. Norton \& Company, Inc,

Aini, Husna. 2013. Sekolah Yang Menyenangkan: Kisah-Kisah Inspiratif Dari Budi Mulia Dua. Yogyakarta: PPSK Press.

Arfani, Junita Widiati. 2013. Sekolah Yang Menyenangkan: Kisah-Kisah Inspiratif Dari Budi Mulia Dua. Yogyakarta: PPSK Press.

Budi, Dinda Upaja. 2014. Angklung Dogdog Lojor pada Upacara Seren Tahun dalam Jurnal Resital, Galang Press, Yogyakarta
Copland, Aaron. 1957. What to Listen for in Music. New York: Crotonville,

Dewanta, siti Nurnisa, 2013. Sekolah Yang Menyenangkan: Kisah-Kisah Inspiratif Dari Budi Mulia Dua. Yogyakarta: PPSK Press.

Don Michael Randel 1986, 'Arangement' dalam The New Harvard Dictionary of Music, London: The Belknap Press of Harvard University Press

Taylor, Eric. 1994. The AB Guide to Music Theory Part I, London: The Assosiated of The Royal School of Music

Haviland, William A. 1993. Antropologi Jilid 2 terj. R.G Soekatijo. Jakarta: Erlangga, 1993

Miller, H.M. 1989 Introduction to Music Guide to Good Listening (penerjemah Triyono Bramantyo). Tidak diterbitkan. Yogyakarta: FSP ISI Yogyakarta.

Moleong, Lexy J. 2005. Metodologi Penelitian Kualitatif, Edisi revisi, Cetakan ke 21, PT. Remaja Rosdakarya, Bandung

Stein, leon. 1979. Structure and Style, The Study And Analysis of Musical Forms, New jersey: SummyBirchard Music,

Syafii, Sulhan, 2009. Udjo Diplomasi Angklung. Jakarta, PT Grasindo, anggota Ikapi.

Soedarsono, R.M [1999]. Metode Penelitian Seni Pertunjukan dan Seni Rupa Masyarakat Seni Pertunjukan Indonesia, Bandung

Sumarsono, Tatang, et al. 2007. Membela Kehormatan Angklung Sebuah Biografi dan Bunga Rampai Daeng Soetigna. Jakarta: Yayasan Serambi Pirous. 
Tim Penulisan Naskah Pengembangan Media Kebudayaan Jawa Barat, et al. 1977. Sejarah Seni Budaya Jawa Barat I. Jakarta: Proyek pengembangan Media Kebudayaan Departemen Pendidikan Dan Kebudayaan.

Watanabe, Ruth T. 1967. Introduction to Music Research. New Jersey: Prentice-Hall, Inc.
Wiramihardja, Obby A.R, Panduan Bermain Angklung. Jakarta: Pusat Penelitian dan Pengembangan Kebudayaan, Badan Pengembangan sumber Daya Kebudayaan dan Pariwisata, Kementerian Kebudayaan dan Pariwisata. 